\title{
What treatments are effective for common cold in adults and children?
}

\author{
Mieke L van Driel professor ${ }^{1}$, Sophie Scheire pharmacist, PhD student ${ }^{2}$, Laura Deckx postdoctoral \\ researcher ${ }^{1}$, Philippe Gevaert professor ${ }^{3}$, An De Sutter professor ${ }^{4}$
}

${ }^{1}$ Faculty of Medicine, University of Queensland, Brisbane, Australia; ${ }^{2}$ Pharmaceutical Care Unit, Faculty of Pharmaceutical Sciences, Ghent University, Ghent, Belgium; ${ }^{3}$ Department of Ear, Nose and Throat, Ghent University, Ghent, Belgium; ${ }^{4}$ Department of Family Medicine and Primary Health Care, Ghent University, Ghent, Belgium

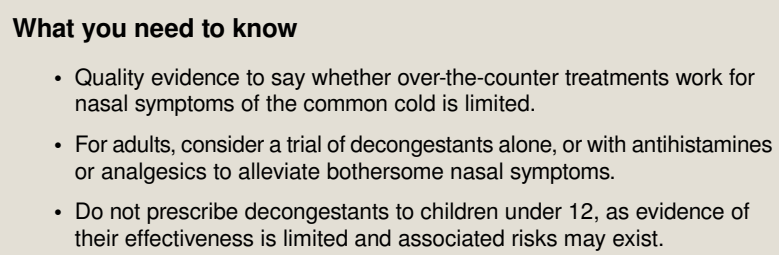

The common cold is usually caused by viruses and is mostly self limiting, ${ }^{1}$ but it can have a substantial impact on work, school, ${ }^{2}$ use of health services, and money spent on medications. Children have around 6-8 colds per year and adults have 2-4. ${ }^{34}$

Many over-the-counter (OTC) treatments for the common cold claim to alleviate nasal symptoms, such as congestion, rhinorrhoea (runny nose), and sneezing. Table 1 lists commonly used drugs. Evidence for the effectiveness of these treatments is limited and of low quality, and clear guidance is lacking. ${ }^{5}$ Long term use of nasal decongestants is known to lead to chronic nasal congestion.

\section{What is the evidence of uncertainty?}

\section{Search strategy and study selection}

We searched the Cochrane Library for systematic reviews that investigate the effectiveness of treatments for the common cold. If only a protocol or no Cochrane review was available, we searched PubMed for other systematic reviews on the topic. If no systematic reviews were found, we searched for individual randomised controlled trials of commonly used treatments (fig 1 , table 2). We extracted data on the subjective severity and duration of nasal symptoms (nasal congestion, rhinorrhoea, and sneezing) and adverse events. We extracted the number of studies and participants, and where available, used pooled results. If pooled results were not available, we assessed whethe the findings were in favour of the active treatment.

\section{Adults}

We found Cochrane reviews on treatments such as decongestants, antihistamines, analgesics, intranasal corticosteroids, herbal remedies, and vitamins and minerals (zinc) in adults with common cold. Commonly reported primary outcomes in the included studies are nasal resistance measures or outcomes such as clinical cure or composite symptom scores. Only a few studies included in these reviews report on bothersome nasal symptoms, such as congestion, rhinorrhoea, and sneezing. In summary, low quality evidence suggests that decongestants (either in monotherapy or in combination with antihistamines and/or analgesics) have a small effect on nasal symptoms (fig 1). Harms include an increased risk of insomnia, drowsiness, headache, or gastrointestinal upset (fig 1, table 2). ${ }^{711}$ Long term use can lead to chronic nasal congestion. However, the recommended safe treatment duration for decongestants varies and seems to be based on expert opinion.

A Cochrane review ${ }^{8}$ (four randomised controlled trials, 1466 participants) shows that sedating antihistamines are associated with relief of rhinorrhoea and sneezing compared with placebo, but not nasal congestion (two randomised controlled trials, 375 participants). Sedation was commonly reported, but there were no differences between groups ( 6 randomised controlled trials, 2265 participants). Studies with non-sedating antihistamines show an unclear effect on congestion (one randomised controlled trial, 53 participants), and no effect on rhinorrhoea (three randomised controlled trials, 838 participants), or sneezing (four randomised controlled trials, 456 participants) and no increased risk of adverse events compared with placebo. ${ }^{8}$

A Cochrane meta-analysis showed no effect of antibiotics on nasal symptoms, but the risk of adverse events was increased. ${ }^{15}$ Evidence does not exist for the effectiveness of antivirals, and intranasal corticosteroids for nasal symptoms in the common 
cold, and their use is not recommended. ${ }^{1232}$

Acetaminophen/paracetamol and NSAIDs are sometimes prescribed for pain relief in common cold, but they do not appear to improve nasal congestion or rhinorrhoea. ${ }^{910}$ Low quality evidence suggests intranasal ipratropium bromide reduces rhinorrhoea compared with placebo, but not nasal congestion. Nosebleeds, nasal dryness, and dry mouth are side effects. ${ }^{13}$

Nasal symptoms are not reported in trials investigating the effect of echinacea, ${ }^{17}$ vitamin $\mathrm{C},{ }^{16}$ zinc lozenges,${ }^{24-26}$ and heated humidified air or steam. ${ }^{21}$ Echinacea does not seem to improve overall symptoms. ${ }^{17}$ Zinc lozenges have been shown to reduce the duration but not severity of cold symptoms, ${ }^{24-26}$ but the optimal composition and dosage of lozenges has not been established. No evidence exists for the use of heated humidified air or steam in the common cold. ${ }^{21} \mathrm{~A}$ Cochrane review concludes that saline irrigations are not likely to be effective in adults. ${ }^{20}$ We did not find trials studying the effect on common cold symptoms for the following treatments: probiotics, ${ }^{27-29}$ garlic, ${ }^{18}$ Chinese medicinal herbs, ${ }^{30}$ vapour rub ${ }^{22}$ eucalyptus oil, honey, ${ }^{31}$ ginseng, ${ }^{23}$ and increased fluid intake. ${ }^{33}$

\section{Children}

Trials are lacking for children under 12, who carry the highest burden of common colds. A Cochrane review found low quality evidence that saline irrigations or drops may be effective and safe in young children. ${ }^{20} \mathrm{~A}$ small number of trials report contradictory results for decongestants and antihistamines on nasal symptoms and safety in children. ${ }^{711}$ Some products that contain decongestant may improve nasal symptoms in children, but their safety, especially in young children, is unclear. We did not find evidence to support the use of other common treatments and home remedies in children (such as heated humidified air or steam, analgesics, echinacea, probiotics, herbs, or vitamins).

\section{Decongestants, antihistamines, and analgesics in monotherapy}

A Cochrane review $^{7}$ (2 randomised controlled trials, 94 participants) comparing oral or intranasal decongestants with placebo found that 3-4 doses per day (over 5 days and up to 10 days) was associated with reduced severity of nasal congestion. Short term adverse events were no different between decongestants and placebo (7 randomised controlled trials, 1195 participants). No trials compared oral with intranasal routes.

A Cochrane review ${ }^{8}$ (4 randomised controlled trials, 1466 participants) shows that sedating antihistamines are associated with relief of rhinorrhoea and sneezing compared with placebo, but not nasal congestion ( 2 randomised controlled trials, 375 participants). Sedation was commonly reported, but there were no differences between groups ( 6 randomised controlled trials, 2265 participants). Studies with non-sedating antihistamines show an unclear effect on congestion (1 randomised controlled trial, 53 participants), and no effect on rhinorrhoea (3 randomised controlled trials, 838 participants), or sneezing (4 randomised controlled trials, 456 participants) and no increased risk of adverse events compared with placebo. ${ }^{8}$

In a Cochrane review ${ }^{9}$ (4 randomised controlled trials, 758 participants), investigating the effect of

acetaminophen/paracetamol compared with placebo on pain and common cold symptoms, only one trial $(n=60)$ reports specific nasal symptoms, noting an unclear effect on severity of symptoms and possible increase of nasal congestion in the acetaminophen group. Adverse events, such as sweating and gastrointestinal upset, were more common with high dose paracetamol $(1000 \mathrm{mg})$ in another trial $(\mathrm{n}=392)$. A pooled analysis of 3 trials $(n=199)$ showed no effect of NSAIDs on nasal congestion or rhinorrhoea compared with placebo, although sneezing was reduced ( 2 randomised controlled trials, $\mathrm{n}=159) .{ }^{16}$ Adverse events, such as rash, oedema and gastro-intestinal complaints, were not different between groups ( 2 randomised controlled trials, $\mathrm{n}=220$ ).

\section{Combinations of decongestants, antihistamines, and analgesics}

A Cochrane review ${ }^{11}$ (27 randomised controlled trials, 5117 participants) evaluated the effect of different combinations of decongestants, antihistamines, and analgesics in the common cold.

Oral antihistamine decongestant combinations ${ }^{11}$ and analgesic decongestant combinations may improve congestion and sneezing, but data could not be pooled because of heterogeneity. Patients taking combinations reported more adverse effects such as sedation, insomnia, and headache. ${ }^{11}$

Of three trials studying oral antihistamine-analgesic combinations, two (341 participants) showed no improvement of nasal congestion compared with placebo or acetaminophen. In one trial (150 participants) the combination was associated with less sneezing. Adverse events (nasal irritation, dry mouth, gastrointestinal upset) occurred in both groups (3 randomised controlled trials, 1508 participants). ${ }^{11}$

Oral antihistamine analgesic decongestant combinations ${ }^{11}$ were consistently associated with reduced nasal congestion and rhinorrhoea compared with placebo (3 randomised controlled trials, 595 participants). It is unclear if adverse events were different between groups.

\section{Ipratropium bromide}

Low quality evidence finds that intranasal ipratropium bromide reduces rhinorrhoea compared with placebo, but not nasal congestion, however there is an increased risk of nosebleeds, nasal dryness, and dry mouth. ${ }^{13}$ A trial with 786 participants reported that decongestant ipratropium bromide combination improved both nasal congestion and rhinorrhoea compared with placebo, with similar adverse events. ${ }^{14}$

\section{Antibiotics}

Antibiotics are not indicated for viral infections such as the common cold. A Cochrane meta-analysis ${ }^{15}$ (6 randomised controlled trials, 1047 participants) showed that antibiotics did not reduce duration of purulent rhinitis (4 randomised controlled trials, 723 participants) or clear rhinitis ( 2 randomised controlled trials, 227 participants), but the risk of adverse events was increased (4 randomised controlled trials, 1267 participants). Effect on congestion was not reported and there was an unclear risk of bias overall.

\section{Antivirals}

A Cochrane review ${ }^{32}$ concludes that none of the licensed antivirals were effective in reducing symptoms, and adverse events make them unacceptable for use in the common cold. This review was withdrawn in 2004 as unpublished data from the original review were not accessible.

\section{Outcomes in children}

Few trials investigate the effect of common cold treatments in children, showing only small effects (fig 1, table 2). In young children (1.5-60 months) sedating antihistamines were associated with shorter duration of rhinorrhoea, ${ }^{8}$ and non-sedating 
antihistamines with shorter duration of overall symptoms, but nasal symptoms were not reported. ${ }^{8}$ Adverse events were either not reported (non-sedating) or not different (sedating). ${ }^{8}$ The Cochrane review on combination treatments for common cold reported that a combination of acetaminophen decongestant antihistamine in children improved nasal congestion on day 5 (although not on day 3) compared with acetaminophen alone. ${ }^{11}$ An NSAID decongestant combination reduced the duration of nasal congestion compared with pseudoephedrine or placebo. ${ }^{11}$ Antihistamine-decongestant combinations did not show consistent effects on nasal symptoms. ${ }^{11}$ Saline nasal irrigation may improve nasal congestion in older children and possibly reduce rhinorrhoea severity. ${ }^{20}$ Vapour rub may improve nasal congestion (not rhinorrhoea), but at an increased risk of adverse events. $^{22}$

A trial with echinacea does not report nasal symptoms, but shows it increases the risk of a rash. ${ }^{17}$ The trial of ginseng did not report nasal symptoms, ${ }^{23}$ nor did studies with honey. ${ }^{5}$ Furthermore, we did not find any trials studying the effect of the following treatments in children with common cold: decongestants in monotherapy, ${ }^{7}$ NSAIDs $^{10}$ or paracetamol ${ }^{9}$ in monotherapy, intranasal corticosteroids, ${ }^{12}$ intranasal ipratropium bromide ${ }^{13}$ antivirals,${ }^{32}$ eucalyptus oil,${ }^{22}$ fluid intake, ${ }^{33}$ garlic, ${ }^{18}$ heated humidified air, ${ }^{21}$ Chinese medicinal herbs,${ }^{30}$ Pelargonium sidoides, ${ }^{19}$ probiotics, ${ }^{27-29}$ vitamin $\mathrm{C},{ }^{16}$ and zinc. ${ }^{2526}$

\section{Is ongoing research likely to provide relevant evidence?}

A search of International Clinical Trials Registry Platform using the terms "common cold" or "respirat*" yielded 17 references to ongoing trials. These trials use analgesic-decongestant-antihistamine combinations $(n=3)$, an intranasal decongestant $(n=1)$, Chinese $(n=3)$ or other herbs $(n=4)$, herbal steam inhalation $(n=1)$, lactic acid bacteria $(n=1)$, pelargonium $(n=1)$, guaifenesin $(n=1)$, and antivirals $(n=2)$. Twelve of these trials include adults (and older children), four include only children, and one includes participants of all ages.

Most of these studies have reasonable sample sizes but few report on nasal symptoms. Five trials explicitly mention they will report on nasal symptoms, and only one of these includes children. Several traditional Chinese, Thai, and Indian herbal treatments are also studied, but none of these trials will provide information about the effect on nasal symptoms. It is unlikely that these will address the uncertainty. No evidence yet exists on the effect of guaifenesin, an expectorant used to treat cough, on nasal symptoms. This study may add to the evidence base.

\section{What should we do in light of the uncertainty?}

The common cold is self limiting and symptoms usually clear within 7 to 10 days. ${ }^{34}$ Explain to patients that there are no "magic bullets" to relieve their symptoms and that very few OTC treatments are supported by evidence.

For adults with bothersome nasal symptoms, decongestants and antihistamines in monotherapy or in combination products are the best choice. However, the effect is small and although the adverse events are usually mild, some-such as sedation-can be disturbing. No evidence suggests that a tablet taken orally or a nasal spray is the more effective. Advise patients to use nasal decongestants for a maximum of 3 to 7 days. ${ }^{35-38}$ Patients often take OTC decongestants before they consult the GP and commonly for more than just a few days. ${ }^{6}$ They may not be aware that prolonged use can lead to chronic nasal congestion (rhinitis medicamentosa). None of the other commonly used OTC treatments have been shown to relieve nasal symptoms and many have not been studied at all. Based on the currently available evidence, reassurance that symptoms are self limiting is the best you can offer patients.

The evidence for common cold treatments in children is more limited. We do not recommend decongestant or formulations containing antihistamine in children under 6 and advise caution between 6 and 12 years. ${ }^{35-38}$ There is no evidence that these treatments alleviate nasal symptoms and they can cause adverse effects such as drowsiness or gastrointestinal upset. Serious harm, such as convulsions, rapid heart rate and death have been linked to decongestant use in very young children. None of the other commonly used OTC and home treatments, such as heated humidified air, eucalyptus oil, or echinacea are supported by adequate evidence.

Explain that a cold is distressing but should pass in 7-10 days. If parents are concerned about their child's comfort, saline nasal irrigations can be given to alleviate nasal symptoms.

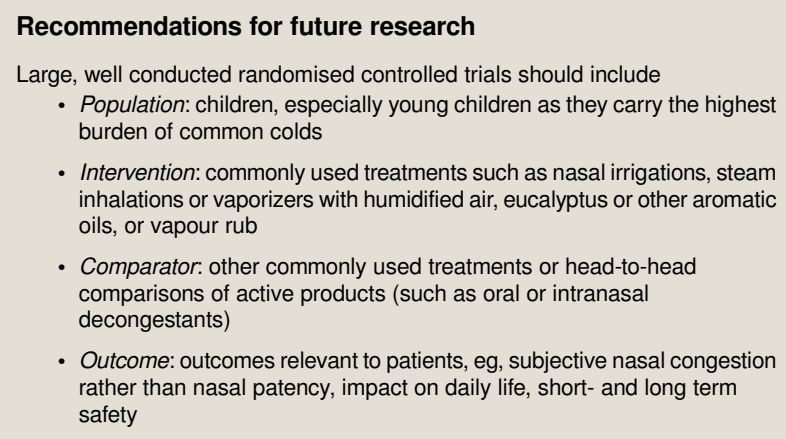

- Comparator. other commonly used treatments or head-to-head comparisons of active products (such as oral or intranasal decongestants)

- Outcome: outcomes relevant to patients, eg, subjective nasal congestion rather than nasal patency, impact on daily life, short- and long term safety

\section{Education into practice}

- How do you discuss treatments for nasal symptoms of the common cold? With an adult? With the parent of a child?

- How would you explore duration of use for decongestant, and how would you address this issue?

\section{What patients need to know}

Common cold is usually self limiting - symptoms clear in 7 to 10 days. Your doctor may offer you medications to relieve headache, pain, or nasal congestion if these are bothersome.

\section{- Adults}

o If a blocked or runny nose, or sneezing related to a cold is bothering you, you can try using nasal decongestants for up to 3 to 7 days o Beware of unintended effects such as drowsiness, insomnia, or headache

o Do not take decongestants longer than advised as long term use may lead to chronic nasal congestion, which is difficult to treat

o Other treatments have either not been effective in clinical trials or have not been studied at all

\section{- In children under 12}

o Saline nasal irrigations or drops can be used safely, but this may not give the desired relief

o Consult a doctor if symptoms are bothersome. Do not give children decongestants

o Vapour rub may relieve congestion but can cause skin rashes

o Other treatments, such as steam, humidified air, echinacea, or probiotics, are either not effective or have not been studied in children. 


\section{Information resources for patients}

NHS Choiceshttp://www.nhs.uk/conditions/Cold-common/Pages/ Introduction.aspx

Definition of common cold, symptoms, treatment, complications, children Free of charge. No registration needed

Mayo Clinichttp://www.mayoclinic.org/diseases-conditions/common-cold/ home/ovc-20199807\#

Overview, symptoms and causes, diagnosis and treatment, self-management. Free of charge. No registration needed

\section{How patients were involved in the creation of this article \\ We asked 10 customers seeking OTC treatments for the common cold in a community pharmacy in Belgium what concerned them most when they had a cold. This revealed a strong focus on managing nasal symptoms. Based on this, we decided to focus on the effect of commonly used treatments on subjective nasal symptoms in common cold. A patient reviewer acknowledged that while there is no clear cut way to resolve symptoms of nasal congestion, appropriate treatment options can be discussed for adults and for children. We have now presented the evidence for common treatments for adults and children separately and also clarified these in the section on 'what patients need to know'.}

Competing interests: We have read and understood the BMJ policy on declaration of interests and declare no relevant financial interests. Mieke van Driel declares payment from IN VIVO Academy Ltd to develop materials for an educational programme on Medication Overuse Headache supported by a competitive unrestricted grant from Pfizer. Philippe Gevaert declared advisory board membership and paid consultancy with Sanofi which produces Dupilumab and Roche which produces Xolair, both for Chronic Rhinosinusitis with nasal polyps.

Provenance and peer review: commissioned; externally peer reviewed.

Contributorship statement and guarantor: MLVD, ADS, and PG developed the outline for the manuscript and identified the uncertainties. LD and SS conducted the searches and drafted the tables and boxes. MLVD drafted the first and revised versions of the manuscript. All authors contributed to writing and critically reviewing the manuscript. MLVD is guarantor.

Funding: The authors had no support from any organisation for the submitted work.

Andrewes $\mathrm{CH}$. The natural history of the common cold. Lancet 1949;1:71-5. 10.1016/S0140-6736(49)90398-0 18236517

2 Hellgren J, Cervin A, Nordling S, Bergman A, Cardell LO. Allergic rhinitis and the common cold--high cost to society. Allergy 2010;65:776-83.

10.1111/i.1398-9995.2009.02269.x 19958315

3 Gwaltney JM. Clinical significance and pathogenesis of viral respiratory infections. Am J Med 2002;112(Suppl 6A):13S-8S. 10.1016/S0002-9343(01)01059-2 11955455

4 Witek TJ, Ramsey DL, Carr AN, Riker DK. The natural history of community-acquired common colds symptoms assessed over 4-years. Rhinology 2015;53:81-8. 10.4193/Rhin14.149 25756083

5 Allan GM, Arroll B. Prevention and treatment of the common cold: making sense of the evidence. CMAJ 2014;186:190-9. . 10.1503/cmaj.121442 24468694

6 Mehuys E, Gevaert P, Brusselle G, etal . Self-medication in persistent rhinitis: overuse of decongestants in half of the patients. J Allergy Clin Immunol Pract 2014;2:313-9. 10.1016/j.jaip.2014.01.009. 10.1016/j.jaip.2014.01.009 24811023

7 Deckx L, De Sutter Al, Guo L, Mir NA, van Driel ML. Nasal decongestants in monotherapy for the common cold. Cochrane Database Syst Rev 2016;10:CD009612.

10.1002/14651858.CD009612.pub2.https://www.ncbi.nlm.nih.gov/entrez/query.fcgi?

$\mathrm{cmd}=$ Retrieve\&db=PubMed\&list_uids=27748955\&dopt=Abstract 27748955

8 De Sutter Al, Saraswat A, van Driel ML. Antihistamines for the common cold. Cochrane Database Syst Rev 2015;11:CD009345. 10.1002/14651858.CD009345.pub2. 26615034

9 Li S, Yue J, Dong BR, Yang M, Lin X, Wu T. Acetaminophen (paracetamol) for the common cold in adults. Cochrane Database Syst Rev 2013;7:CD008800.

10.1002/14651858.CD008800.pub2.https://www.ncbi.nlm.nih.gov/entrez/query.fcgi? $\mathrm{cmd}=$ Retrieve\&db=PubMed\&list_uids=23818046\&dopt=Abstract 23818046

$10 \mathrm{Kim}$ SY, Chang YJ, Cho HM, Hwang YW, Moon YS. Non-steroidal anti-inflammatory drugs for the common cold. Cochrane Database Syst Rev 2015;9:CD006362. 10.1002/14651858.CD006362.pub4.https://www.ncbi.nlm.nih.gov/entrez/query.fcgi? $\mathrm{cmd}=$ Retrieve\&db=PubMed\&list uids=26387658\&dopt=Abstract 26387658

11 De Sutter Al, van Driel ML, Kumar AA, Lesslar O, Skrt A. Oral

antihistamine-decongestant-analgesic combinations for the common cold. Cochrane Database Syst Rev2012;15:CD004976. 10.1002/14651858.CD004976.pub3.https://www.
ncbi.nlm.nih.gov/entrez/query.fcgi?cmd=Retrieve\&db=PubMed\&list_uids=22336807\& dopt=Abstract 22336807

12 Hayward G, Thompson MJ, Perera R, Del Mar CB, Glasziou PP, Heneghan CJ. Corticosteroids for the common cold. Cochrane Database Syst Rev 2015;10:CD008116. 10.1002/14651858.CD008116.pub3.https://www.ncbi.nlm.nih.gov/entrez/query.fcgi? $\mathrm{cmd}=$ Retrieve\&db=PubMed\&list_uids=26461493\&dopt=Abstract 26461493

13 AlBalawi ZH, Othman SS, Alfaleh K. Intranasal ipratropium bromide for the common cold. Cochrane Database Syst Rev 2013;6:CD008231.

10.1002/14651858.CD008231.pub3.https://www.ncbi.nlm.nih.gov/entrez/query.fcgi? cmd=Retrieve\&db=PubMed\&list_uids=23784858\&dopt=Abstract 23784858

14 Eccles R, Martensson K, Chen SC. Effects of intranasal xylometazoline, alone or in combination with ipratropium, in patients with common cold. Curr Med Res Opin 2010;26:889-99. 10.1185/03007991003648015 20151787

15 Kenealy T, Arroll B. Antibiotics for the common cold and acute purulent rhinitis. Cochrane Database Syst Rev 2013;6:CD000247. 10.1002/14651858.CD000247.pub3.https://www. ncbi.nlm.nih.gov/entrez/query.fcgi?cmd=Retrieve\&db=PubMed\&list_uids=23733381\& dopt=Abstract 23733381

16 Hemilä H, Chalker E. Vitamin C for preventing and treating the common cold. Cochrane Database Syst Rev 2013;(1):CD000980. 10.1002/14651858.CD000980.pub4.https://www. ncbi.nlm.nih.gov/entrez/query.fcgi?cmd=Retrieve\&db=PubMed\&list_uids=23440782\& dopt=Abstract 23440782

17 Karsch-Völk M, Barrett B, Kiefer D, Bauer R, Ardjomand-Woelkart K, Linde K. Echinacea for preventing and treating the common cold. Cochrane Database Syst Rev 2014;2:CD000530. 10.1002/14651858.CD000530.pub3. 24554461

18 Lissiman E, Bhasale AL, Cohen M. Garlic for the common cold. Cochrane Database Syst Rev 2014;11:CD006206. 10.1002/14651858.CD006206.pub4

19 Timmer A, Günther J, Motschall E, Rücker G, Antes G, Kern WV. Pelargonium sidoides extract for treating acute respiratory tract infections. Cochrane Database Syst Rev 2013;10:CD006323. 10.1002/14651858.CD006323.pub3. 24146345

20 King D, Mitchell B, Williams CP, Spurling GK. Saline nasal irrigation for acute upper respiratory tract infections. Cochrane Database Syst Rev 2015;20:CD006821. 10.1002/14651858.CD006821.pub3. 25892369

21 Singh M, Singh M, Jaiswal N, Chauhan A. Heated, humidified air for the common cold. Cochrane Database Syst Rev 2017;8:CD001728. 10.1002/14651858.CD001728.pub6. 28849871

22 Paul IM, Beiler JS, King TS, Clapp ER, Vallati J, Berlin CMJr. Vapor rub, petrolatum, and no treatment for children with nocturnal cough and cold symptoms. Pediatrics 2010;126:1092-9. 10.1542/peds.2010-1601 21059712

23 Vohra S, Johnston BC, Laycock KL, etal. Safety and tolerability of North American ginseng extract in the treatment of pediatric upper respiratory tract infection: a phase II randomized, controlled trial of 2 dosing schedules. Pediatrics 2008;122:e402-10. 10.1542/peds.2007-2186 18676527

24 Singh M, Das RR. WITHDRAWN: Zinc for the common cold. Cochrane Database Syst Rev 2015;4:CD001364. 10.1002/14651858.CD001364.pub5. 25924708

25 Hemilä $\mathrm{H}$. Zinc lozenges and the common cold: a meta-analysis comparing zinc acetate and zinc gluconate, and the role of zinc dosage. JRSM Open 2017;8:2054270417694291. 10.1177/205427041769429128515951

26 Hemilä H, Petrus EJ, Fitzgerald JT, Prasad A. Zinc acetate lozenges for treating the common cold: an individual patient data meta-analysis. Br J Clin Pharmacol 2016;82:1393-8. 10.1111/bcp.13057 27378206

27 Araujo GV, Oliveira Junior MH, Peixoto DM, Sarinho ES. Probiotics for the treatment of upper and lower respiratory-tract infections in children: systematic review based on randomized clinical trials. J Pediatr (Rio J) 2015;91:413-27. 10.1016/j.jped.2015.03.002 26054771

28 Wang $\mathrm{Y}, \mathrm{Li} \mathrm{X}, \mathrm{Ge} \mathrm{T}$, etal . Probiotics for prevention and treatment of respiratory tract infections in children: A systematic review and meta-analysis of randomized controlled trials. Medicine (Baltimore) 2016;95:e4509 . 10.1097/MD.0000000000004509 27495104

29 Robinson JL. Probiotics for modification of the incidence or severity of respiratory tract infections. Pediatr Infect Dis J 2017;36:1093-5. 10.1097/INF.0000000000001714 28767618

30 Wu T, Zhang J, Qiu Y, Xie L, Liu GJ. Chinese medicinal herbs for the common cold. Cochrane Database Syst Rev 2007;1:CD004782. 10.1002/14651858.CD004782.pub2. 17253524

31 Smith SM, Schroeder K, Fahey T. Over-the-counter (OTC) medications for acute cough in children and adults in community settings. Cochrane Database Syst Rev 2014;11:CD001831. 10.1002/14651858.CD001831.pub5. 25420096

32 Jefferson TO, Tyrrell D. WITHDRAWN: Antivirals for the common cold. Cochrane Database Syst Rev 2007;3:CD002743. 17636705

33 Guppy MP, Mickan SM, Del Mar CB, Thorning S, Rack A. Advising patients to increase fluid intake for treating acute respiratory infections. Cochrane Database Syst Rev 2011;2:CD004419.21328268

34 Lorber B. The common cold. J Gen Intern Med 1996;11:229-36. 874488

35 NHS Choices. Decongestants 2016. https://www.nhs.uk/conditions/decongestants/\#howto-use-decongestants

36 Therapeutic Guidelines Ltd. Ear, nose and throat infections Melbourne, Australia 2014 https://tgldcdp.tg.org.au/viewTopic?topicfile=ear-nose-throat-infections\& guidelineName=Antibiotic\#toc_d1e888.

37 Government of Canada. Guidance document-Nonprescription topical nasal decongestants labelling standard 2014. https://www.canada.ca/en/health-canada/services/drugs-healthproducts/drug-products/applications-submissions/guidance-documents/nonprescriptiondrugs-labelling-standards/nonprescription-topical-nasal-decongestants-labelling-standard. html\#s5.1

38 Therapeutic Goods Administration. OTC medicine monograph: Topical nasa decongestants: Australian Government Department of Health. 2014. https://www.tga.gov. au/otc-medicine-monograph-topical-nasal-decongestants.

Published by the BMJ Publishing Group Limited. For permission to use (where not already granted under a licence) please go to http://group.bmj.com/group/rights-licensing/ permissions 


\section{Tables}

\section{Table $1 \mid$ Drugs used to treat symptoms in common cold}

\section{Decongestant}

\begin{tabular}{|c|c|}
\hline Sympathomimetic: oral & Ephedrine hydrochloride, pseudoephedrine hydrochloride, phenylephrine hydrochloride \\
\hline Sympathomimetic: intranasal & Naphazoline nitrate, oxymetazoline hydrochloride, tramazoline hydrochloride, xylometazoline hydrochloride \\
\hline \multicolumn{2}{|l|}{ Antihistamine } \\
\hline Older, "first generation," sedating & $\begin{array}{l}\text { Alimemazine tartrate, chlorphenamine maleate, clemastine, cyproheptadine hydrochloride, dimethindene } \\
\text { maleate, hydroxyzine hydrochloride ketotifen, promethazine hydrochloride }\end{array}$ \\
\hline Newer, "second generation," non-sedating & $\begin{array}{l}\text { Acrivastine, azelastine hydrochloride, blotine, cetirizine hydrochloride, desloratadine, fexofenadine } \\
\text { hydrochloride, levocabastiblobdrochloride, levocetirizine hydrochloride, loratadine, mizolastine, } \\
\text { olopatadine hydrochloride }\end{array}$ \\
\hline \multirow[t]{3}{*}{ Analgesic } & Acetaminophen/paracetamol \\
\hline & Non-steroidal anti-inflammatory drugs (NSAIDs): \\
\hline & acetylsalicylic acid (aspirin), ibuprofen, naproxen \\
\hline Nasal corticosteroids & $\begin{array}{l}\text { Beclomethasone diproprionate, budesonide, ciclesonide, fluticasone furoate/propionate, flunisolide, } \\
\text { mometasone furoate, triamcinolone acetonide }\end{array}$ \\
\hline Antimuscarinic & Ipratropium bromide \\
\hline Saline nasal irrigation & Sodium chloride $0.9 \%$ (saline) \\
\hline
\end{tabular}

Availability and OTC status of the products vary by country

* Both oral and intranasal

** Intranasal 


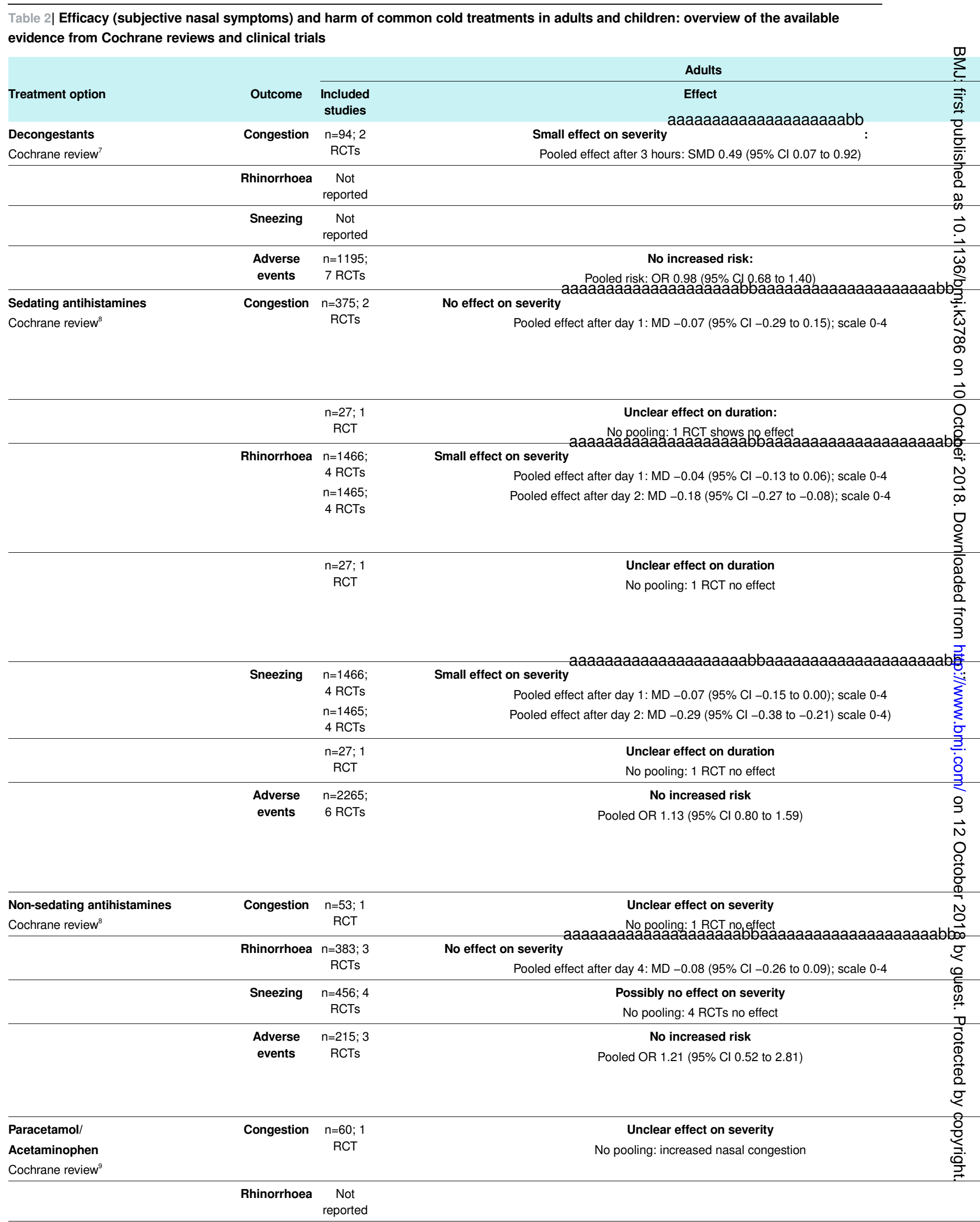


Table 2 (continued)

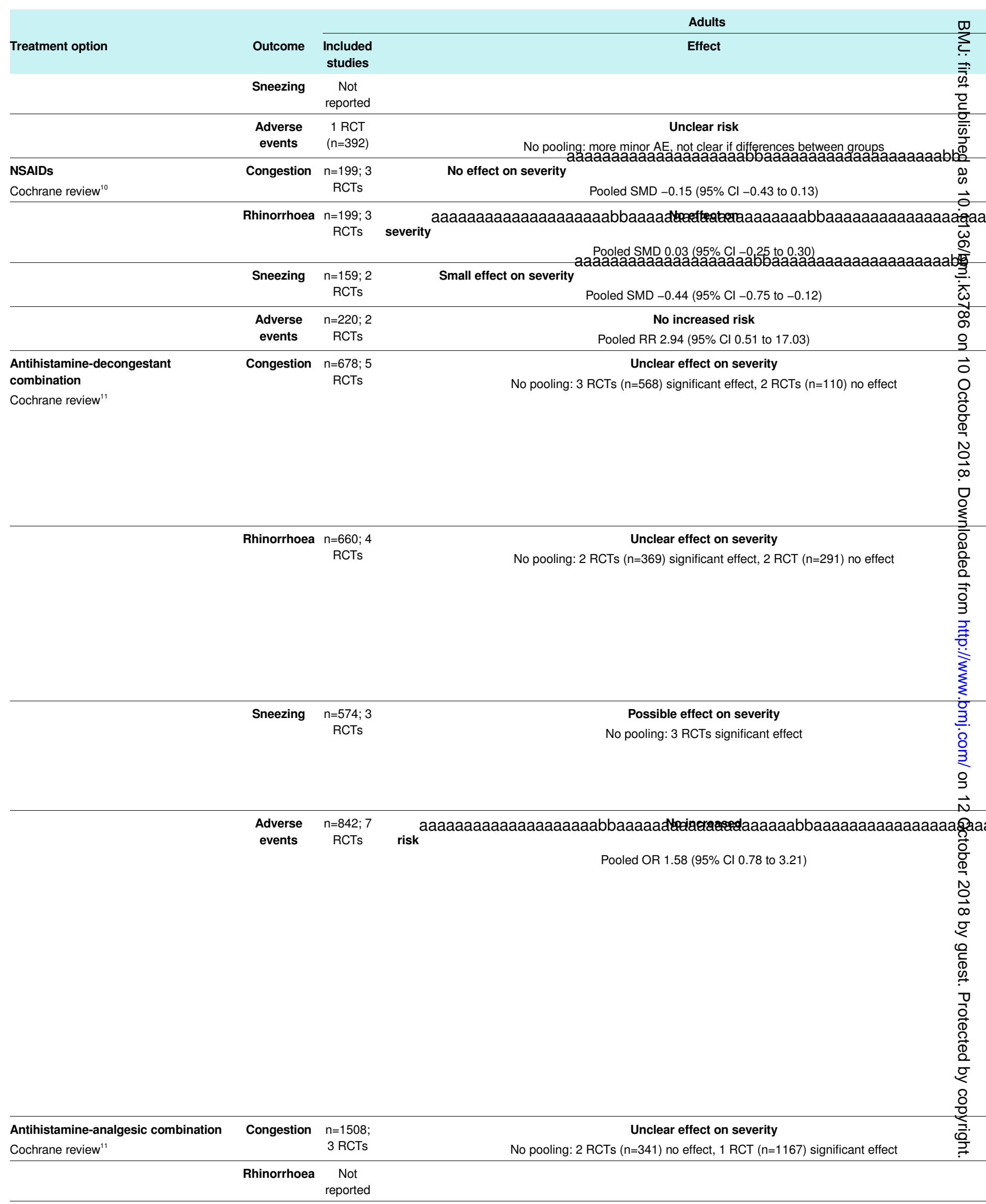


Table 2 (continued)

\begin{tabular}{|c|c|c|c|}
\hline Treatment option & Outcome & & Adults \\
\hline & $\begin{array}{l}\text { Adverse } \\
\text { events }\end{array}$ & $\begin{array}{l}\mathrm{n}=1508 \\
3 \text { RCTs }\end{array}$ & $\begin{array}{c}\text { Possibly no increased risk } \\
\text { No pooling: } 3 \text { RCTs no difference in } A E\end{array}$ \\
\hline
\end{tabular}

\begin{tabular}{|c|c|c|}
\hline & $\begin{aligned} \text { Rhinorrhoea } n=679 ; 3 \\
\text { RCTs }\end{aligned}$ & $\begin{array}{l}\text { Possibly no effect on severity } \\
\text { No pooling: } 3 \text { RCTs no effect }\end{array}$ \\
\hline & $\begin{array}{l}\mathrm{n}=621 ; 2 \\
\mathrm{RCTs}\end{array}$ & $\begin{array}{l}\text { Possibly no effect on severity } \\
\text { No pooling: } 2 \text { RCTs no effect }\end{array}$ \\
\hline & $\begin{array}{l}\text { Adverse } \\
\text { events }\end{array}$ & $\begin{array}{c}\text { Increased risk } \\
\text { Pooled OR } 1.71(95 \% \mathrm{Cl} 1.23 \text { to } 2.37 ; \mathrm{NNH} 14)\end{array}$ \\
\hline $\begin{array}{l}\text { Antihistamine-analgesic-decongestant } \\
\text { combination } \\
\text { Cochrane review }{ }^{11}\end{array}$ & Congestion $\begin{aligned} n=595 ; 3 \\
\text { RCTs }\end{aligned}$ & $\begin{array}{c}\text { Possible effect on severity } \\
\text { No pooling: } 3 \text { RCTs significant effect }\end{array}$ \\
\hline
\end{tabular}

Rhinorrhoea $n=595 ; 3$

RCTs
Possible effect on severity

No pooling: 3 RCTs significant effect

\begin{tabular}{cc}
\hline Sneezing & $\begin{array}{c}n=70 ; 1 \\
\text { RCT }\end{array}$ \\
\hline $\begin{array}{cc}\text { Adverse } \\
\text { events }\end{array}$ & $\begin{array}{c}n=595 ; 3 \\
\text { RCTs }\end{array}$
\end{tabular}

Unclear effect on severity

No pooling: no effect

Unclear risk

No pooling: unclear if differences between groups

\begin{tabular}{|c|c|c|}
\hline $\begin{array}{l}\text { Intranasal corticosteroids } \\
\text { Cochrane review }^{12}\end{array}$ & Congestion & $\begin{array}{l}\text { Not } \\
\text { reported }\end{array}$ \\
\hline & Rhinorrhoea & $\begin{array}{c}\text { Not } \\
\text { reported }\end{array}$ \\
\hline & Sneezing & $\begin{array}{c}\text { Not } \\
\text { reported }\end{array}$ \\
\hline & $\begin{array}{c}\text { Adverse } \\
\text { events }\end{array}$ & $\begin{array}{c}\mathrm{n}=200 ; 1 \\
\mathrm{RCTs}\end{array}$ \\
\hline \multirow[t]{4}{*}{$\begin{array}{l}\text { Intranasal ipratropium bromide } \\
\text { Cochrane review }^{13}\end{array}$} & Congestion & $\begin{array}{l}\mathrm{n}=1081 \\
4 \text { RCTs }\end{array}$ \\
\hline & Rhinorrhoea & $\begin{array}{c}\mathrm{n}=1959 \\
4 \text { RCTs }\end{array}$ \\
\hline & Sneezing & $\begin{array}{c}\text { Not } \\
\text { reported }\end{array}$ \\
\hline & $\begin{array}{l}\text { Adverse } \\
\text { events }\end{array}$ & $\begin{array}{l}\text { No RCTs } \\
\text { available }\end{array}$ \\
\hline
\end{tabular}

No pooling: no differences

Possibly no effect on severity

No pooling: 4 RCTs no significant effect

Possible effect on severity

No pooling: 4 RCTs significant effect

Increased risk

Epistaxis: OR 3.21 (95\% Cl 1.68 to 6.13$)$

Nasal dryness: OR 2.55 (1.50 to 4.33 )

Dry mouth: OR 3.59 (1.38 to 9.38)

Other AE: not significant

Decongestant - ipratropium bromide Congestion $\mathrm{n}=786 ; 1$
combination

Unclear effect on severity

No pooling: significant effect after $24 \mathrm{hrs}$ 
Table 2 (continued)

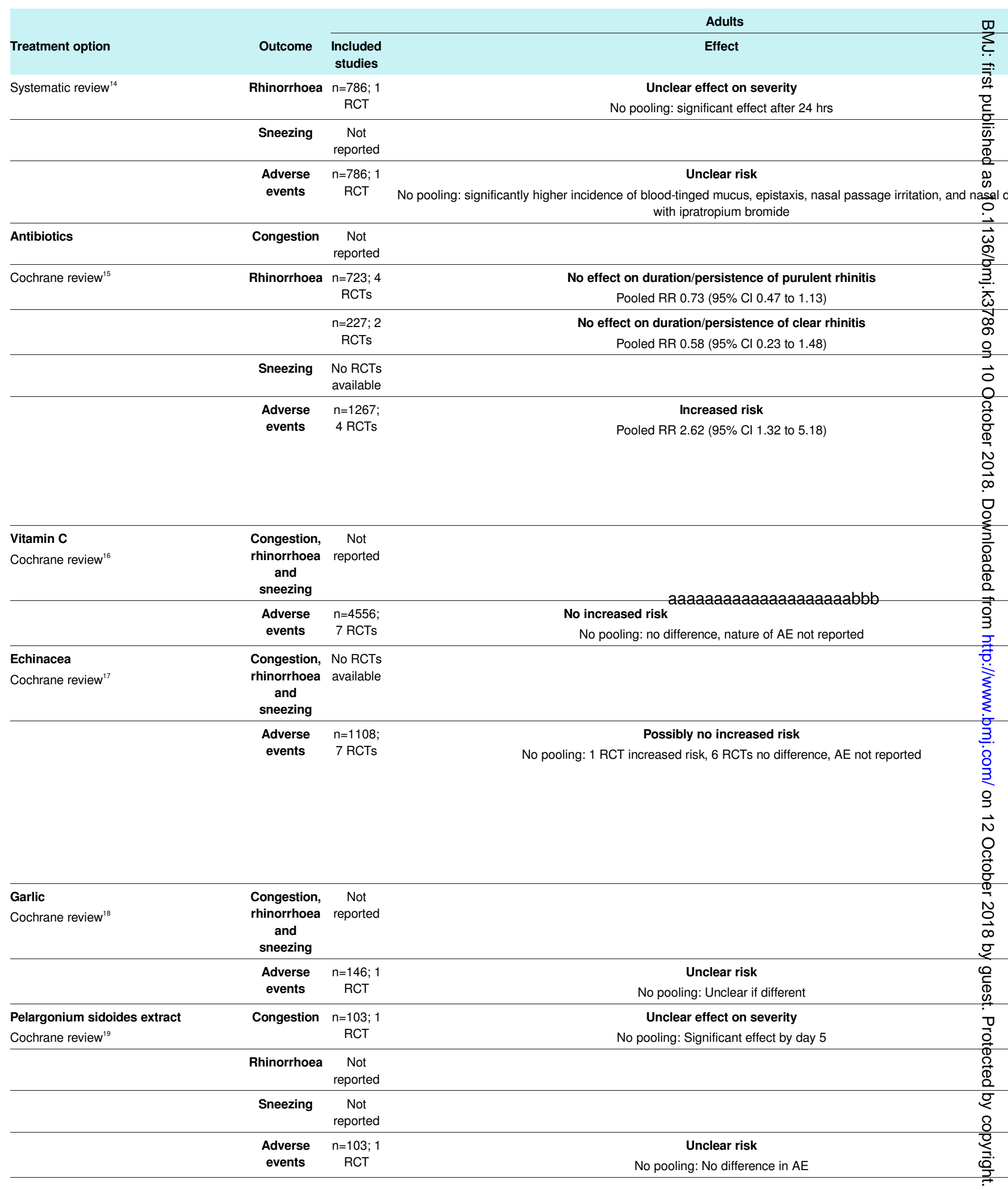


Table 2 (continued)

\begin{tabular}{|c|c|c|c|}
\hline Treatment option & Outcome & & Adults \\
\hline Cochrane review ${ }^{20}$ & & RCTs & No pooling: 2 RTCs no effect on day 3 \\
\hline
\end{tabular}

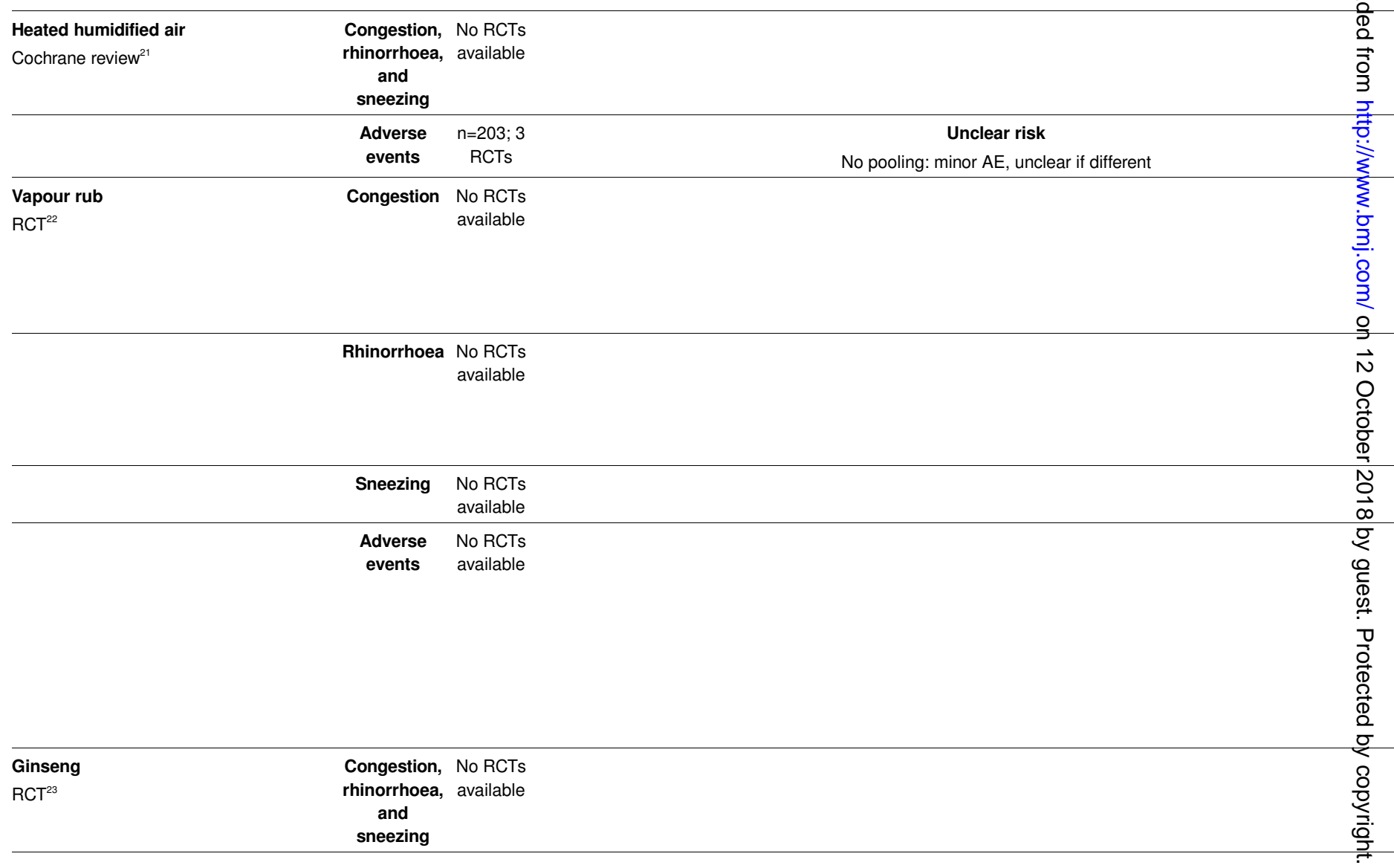


Table 2 (continued)

\begin{tabular}{cccc} 
& & & Adults \\
\cline { 3 - 4 } Treatment option & Outcome & $\begin{array}{c}\text { Included } \\
\text { studies }\end{array}$ & Effect \\
& Adverse & No RCTs \\
events & available & ave
\end{tabular}

\section{Antivirals $^{\mathrm{v} 20}$,}

Congestion, No RCTs

zinc,${ }^{24}-{ }^{26}$ probiotics, ${ }^{27}-{ }^{29}$ Chinese medicinal rhinorrhoea, available

herbs,${ }^{30}$ honey, ${ }^{31}$ eucalyptus oil, ${ }^{22}$ fluid

sneezing

intake $^{\text {vi } 36}$

and adverse

events

"No effect" indicates that data were pooled and the overall effect estimate was not statistically significant. A "possible effect" is based on a qualitative appreciation of the effects size was based on what the authors reported and on the Cochrane Handbook (eg, a standardised mean difference of 0.2 to 0.49 represents a small, 0.5 to 0.79 a moderate, and results were consistent, we concluded there was a possible effect or possibly no effect. Quality of evidence was based on the GRADE assessment reported in the review (indicate review we assigned a GRADE assessment (see supplementary table); NSAIDs: non-steroidal anti-inflammatory drugs; GI: gastrointestinal; AE: adverse events; CI: confidence intöval; risk.

Positive scores represent treatment benefit;

aaaaaaaaaaaaaaaaaaaabbaaaaaaaaaaaaaaaaaaaabb

Tihis meta-analysis included one study that might have included children $(n=60)$, although the age of the participants was not clear

It was not clear from the review which studies recorded adverse events, therefore we were not able to differentiate between adults and children

The review on antivirals has been withdrawn, no new updated Cochrane review has been published

Vhe review on fluid intake did not identify any relevant trials 


\section{Figure}




\begin{tabular}{l} 
ADULTS \\
Analgesic-decongestant combination \\
Antihistamine-analgesic-decongestant combination \\
\hline Antihistamine-decongestant combination \\
\hline Decongestants \\
\hline Intranasal ipratropium bromide \\
\hline NSAIDs \\
\hline Sedating antihistamines \\
\hline Non-sedating antihistamines \\
\hline Antihistamine-analgesic combination \\
\hline Decongestant - ipratropium bromide combination \\
\hline Paracetamol/Acetaminophen \\
\hline Pelargonium sidoides extract \\
\hline Saline nasal irrigation \\
\hline Antibiotics \\
\hline Echinacea \\
Corticosteroids \\
No trials available for: Antivirals, Chinese medicinal herbs, \\
Vapour rub, Zinc \\
\hline intid intake, Ginseng, Honey, Probiotics, \\
\hline
\end{tabular}

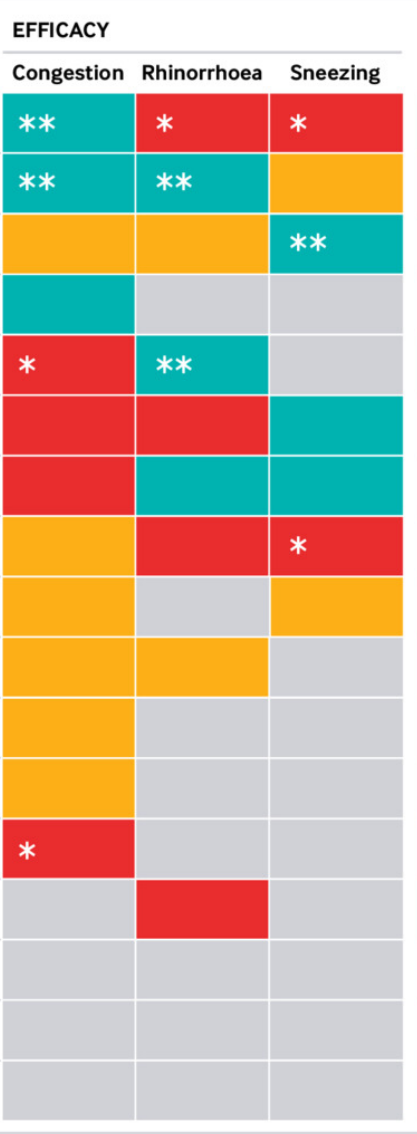

No effect/*possibly no effect

- Small effect/ ${ }^{* *}$ possible small effect

Unclear

Not reported
HARM

\section{Risk of harm Reported adverse events}

Sedation, insomnia, nervousness, palpitations, light headedness, Gl symptoms, dizziness, dry mouth, headache, fever

Sedation, insomnia, dizziness, palpitations, headache and Gl symptoms

Sedation, dry mouth, insomnia, Gl symptoms, dizziness, palpitations, nervousness and headache

Insomnia and headache

Nosebleeds, dryness of nose/eyes/mouth, nasal irritation, headache, tachycardia

Drowsiness, Gl symptoms, rash, oedema, hyperactivity, flushed face, insomnia, light-headedness, dry mouth

Sedation, Gl symptoms, insomnia, dry nose, headache, dizziness and dry mouth

Sedation, Gl symptoms, insomnia, dry nose, headache, dizziness and dry mouth

Nasal dryness/irritation, drowsiness, dizziness dry mouth, Gl symptoms, appetite loss, headache, depression, epistaxis

Blood-tinged mucus, epistaxis, nasal dryness/irritation, headache, dry throat/mouth, nausea, throat irritation

Sweating and GI symptoms

Gl symptoms and allergic skin reactions

Dry nose, nasal pain/irritation

\section{Gl symptoms}

Unclear which adverse events occurred

$* * *$

Unclear which adverse events occurred

Garlic: rash and odour; Heated air: nasal/lip irritation, light-headedness, congestion, discomfort of mask

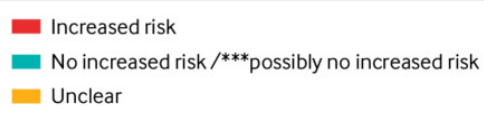

No increased risk /***possibly no increased risk - Unclear

Fig. 1 Benefit and harm of common cold treatments in adults and children: a summary based on analysis of the evidence from Cochrane reviews and clinical trial. "No effect" indicates that data were pooled and the overall effect estimate was not statistically significant. A "possible" effect is based on a qualitative appreciation of the effects reported in individual trials that could not be pooled. Interpretation of the size of the effect was based on what the authors reported and on the Cochrane Handbook (eg, a standard mean difference of 0.2 to 0.49 represents a small, 0.5 to 0.79 a moderate, and $\geq 0.8$ a large clinical effect). If no pooling was available but results were consistent, we concluded there 
was a possible effect or possibly no effect. * The Cochrane review on antivirals has been withdrawn, no new updated Cochrane review has been published. ${ }^{\dagger}$ The Cochrane review on fluid intake did not identify any relevant trials 